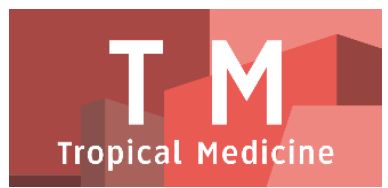

PAPER - OPEN ACCESS

\title{
Pengalaman Ibu Usia Remaja Dalam Merawat Bayi Berat Lahir Rendah (BBLR) Di Kota Medan: Studi Fenomenologis
}

\author{
Author : Widy Santri Ningsih \\ DOI $\quad: 10.32734 / \mathrm{tm} . v 1 i 1.61$ \\ Paper Page : $53-58$
}

Volume 1 Issue 1 - 2018 TALENTA Conference Series: Tropical Medicine (TM)

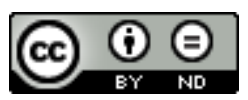

This work is licensed under a Creative Commons Attribution-NoDerivatives 4.0 International License.

Published under licence by TALENTA Publisher, Universitas Sumatera Utara
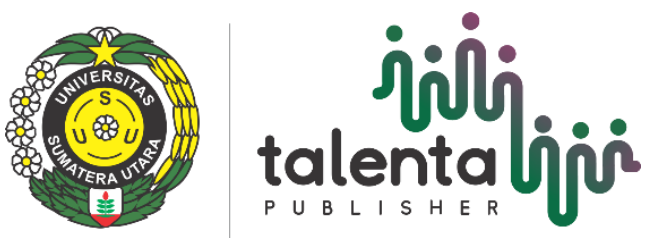


\title{
Pengalaman Ibu Usia Remaja Dalam Merawat Bayi Berat Lahir Rendah (BBLR) Di Kota Medan: Studi Fenomenologis
}

\author{
Widy Santri Ningsih ${ }^{\mathrm{a}, *}$, Setiawan ${ }^{\mathrm{a}}$ \\ ${ }^{a}$ Fakultas Keperawatan, Universitas Sumatera Utara, Medan 20155, Indonesia \\ widysantriningsih@students.usu.ac.id, setiawan@usu.ac.id
}

\begin{abstract}
Abstrak
Bayi Berat Lahir Rendah (BBLR) adalah bayi baru lahir yang berat badannya kurang dari 2.500 gram (sampai dengan 2.499 gram). BBLR merupakan penyebab utama dalam mortalitas, morbiditas dan kecacatan pada neonatus, balita dan anak-anak serta memiliki efek yang sangat panjang dalam kesehatan dewasa nantinya. Penelitian ini bertujuan untuk mengeksplorasi pengalaman ibu usia remaja dalam merawat bayi berat lahir rendah di Kota Medan. Desain penelitian yang digunakan adalah studi fenomenologi. Teknik pengambilan sampel yang digunakan adalah purposive sampling dengan jumlah partisipan sebanyak sepuluh orang. Kriteria partisipan adalah ibu remaja usia 17-20 tahun yang melahirkan bayi berat lahir rendah dan mempunyai pengalaman merawat bayi berat lahir rendah di rumah. Penelitian ini dilaksanakan di satu rumah sakit dan satu klinik bersalin. Penelitian ini dimulai tanggal 16 Februari 2016 sampai 30 April 2016. Analisa data menggunakan metode Colaizzi. Hasil penelitian ini didapatkan lima tema pengalaman ibu usia remaja dalam merawat bayi berat lahir rendah, yaitu (1) mengupayakan pengobatan untuk BBLR; (2) memberikan perawatan khusus pada BBLR; (3) mengalami keterbatasan dalam kegiatan sosialisasi; (4) menderita secara fisik, psikologis dan emosional saat merawat BBLR; dan (5) mendapat dukungan dari pihak keluarga dan tenaga kesehatan. Berdasarkan hasil penelitian, diharapkan agar pelayanan keperawatan dapat memberikan asuhan keperawatan secara holistik pada ibu remaja dalam perawatan bayi berat lahir rendah di rumah..
\end{abstract}

Kata Kunci: Pengalaman; Ibu Usia Remaja; Bayi Berat Lahir Rendah.

\section{Pendahuluan}

Bayi Berat Lahir Rendah merupakan penyebab utama dalam mortalitas, morbiditas dan kecacatan pada neonatus, balita dan anak-anak serta memiliki efek yang sangat panjang dalam kesehatan dewasa nantinya [8]. BBLR adalah bayi baru lahir yang berat badannya kurang dari 2.500 gram (sampai dengan 2.499 gram), sebagai akibat dari prematuritas atau gangguan pertumbuhan di dalam uterus (intrauterine growth retardation) [7]. World Health Organization [15] menyatakan bahwa bayi yang lahir dengan berat badan kurang dari 2500 gram atau sama dengan 2500 gram (5,5 pound) disebut LBW (Low Birth Weight). Kehamilan pada masa remaja mempunyai resiko medis yang cukup tinggi, beresiko melahirkan bayi berat lahir rendah dan prematur karena alat reproduksi belum cukup matang untuk melakukan fungsinya dan rahim (uterus) baru siap melakukan fungsinya setelah umur 20 tahun, karena pada usia ini fungsi hormonal akan bekerja maksimal [2].

Remaja yang hamil biasanya mengalami tekanan emosional, malu, depresi, dan kemungkinan besar tidak melanjutkan sekolah [2]. Konflik yang dialami akan meningkat pada saat terjadinya interaksi antara tuntutan dari lingkungan sosial remaja dengan kewajibannya merawat bayi. Sebagai remaja, kebutuhan bersosialisasi sangat tinggi, karena itu pekerjaan merawat bayi seringkali dirasakan membebani dan mengganggu dunia remaja, apalagi merawat bayi dengan berat badan lahir rendah (BBLR) [3]. Banyak tugas perkembangan yang tidak dapat 
diselesaikan oleh remaja akibat tuntutan untuk menjalankan peran barunya sebagai orang dewasa, padahal dalam perkembangannya yang normal remaja harus menyelesaikan tugasnya terlebih dahulu, kemudian memasuki tahap perkembangan selanjutnya [2].

Remaja yang memiliki bayi BBLR merasa tidak mampu memberikan perawatan yang sesuai, tidak percaya diri dalam merawat bayi BBLR karena merasa takut dan khawatir akan kemampuannya [8]. Selain itu, ibu remaja jelas belum siap merawat bayi dan tidak dapat memberikan stimulasi, beresiko gangguan pemberian ASI, dan bayinya akan rentan terkena gangguan pertumbuhan dan mudah infeksi [3].

\section{Metode Penelitian}

Penelitian ini menggunakan desain fenomenologi. Partisipan dalam penelitian ini terdiri dari sepuluh orang ibu usia remaja (17-21 tahun) yang melahirkan bayi berat lahir rendah di Klinik Bersalin Sumiariani dan Rumah Sakit Ibu dan Anak Badrul Aini. Pemilihan partisipan dalam penelitian ini dengan menggunakan metode purposive sampling yaitu metode pemilihan partisipan dalam suatu penelitian dengan menentukan terlebih dahulu kriteria yang akan dimasukkan dalam penelitian [10].

Pengumpulan data dilakukan dengan in-depth interview. Proses analisa data dilakukan segera setelah selesai setiap satu proses wawancara, yaitu bersamaan dengan dibuatnya transkrip wawancara. Data yang diperoleh dianalisis dengan menggunakan metode Collaizi. Pengumpulan data dilakukan setelah mendapat izin dari Dekan Fakultas Keperawatan Universitas Sumatera Utara dan memperoleh ethical clearance dari Komisi Etik Penelitian Kesehatan Fakultas Keperawatan Universitas Sumatera Utara. Selanjutnya peneliti menjelaskan tujuan, manfaat dan prosedur pelaksanaan penelitian kepada calon partisipan dan bila partisipan bersedia berpartisipasi dalam penelitian ini maka partisipan diminta untuk menandatangi surat persetujuan sebagai partisipan (informed consent).

\section{Hasil Penelitian}

Penelitian ini menemukan ada 5 tema terkait dengan pengalaman ibu usia remaja dalam merawat bayi berat lahir rendah (BBLR) di Kota Medan, yaitu (1) mengupayakan pengobatan untuk BBLR; (2) memberikan perawatan khusus pada BBLR; (3) mengalami keterbatasan kegiatan sosialisasi; (4) menderita secara fisik, psikologis, dan emosional; dan (5) mendapat dukungan dari pihak keluarga dan tenaga kesehatan.

\subsection{Mengupayakan Pengobatan untuk BBLR}

Partisipan dalam penelitian ini mengatakan bahwa melakukan pengobatan dari pelayanan kesehatan karena mereka percaya akan pengobatan yang dilakukan oleh tim medis hal ini dilakukan oleh pasien karena penyakit yang dialami oleh partisipan adalah penyakit medis yang seharusnya di bawa ke pelayanan kesehatan. Berikut pernyataan partisipan:

"Partisipan dalam penelitian ini menyatakan bahwa mereka lebih memilih membawa bayi yang sakit berobat ke dokter dan bidan untuk mendapatkan pelayanan kesehatan. Hal ini sesuai dengan pernyataan dibawah ini: "Kalo sakit ya saya bawa ke dokter spesialis anak, buka praktek di rumahnya selalu saya bawa kesitu, imunisasi juga disitu kalo minum obat gitu kan gak sampe 3 hari sembuhlah dia"

(Partisipan 1)

Partisipan yang lain juga mengatakan bahwa bayi pernah dibawa berobat kampung dan memberikan jamu kepada bayi berat lahir rendah. Hal ini sesuai dengan pernyataan di bawah ini:

"Udah dikasih makan gak mau diam, dikasi susu juga gak mau diam. Terakhir, kakak bawa ke tempat orang tua sana, adalah dulu kakek-kakek kan, ntah diapain sama dia baru dia agak lumayan nangisnya"

(Partisipan 4) 


\subsection{Memberikan Perawatan Khusus pada BBLR}

Partisipan mengatakan bahwa memberikan imunisasi kepada bayi berat lahir rendah merupakan suatu keharusan agar bayi tidak mudah terserang penyakit. Partisipan juga mengatakan bahwa imunisasi dilakukan di rumah sakit atau di sarana pelayanan kesehatan lainnya, misalnya di posyandu. Hal tersebut sesuai dengan pernyataan partisipan berikut ini: 4)

"Kalo imunisasi memang lengkap, wajiblah diimunisasi anakku ini biar gak sakit-sakit aja kerjanya" (Partisipan

Partisipan yang lain juga mengatakan bahwa mereka memberikan ASI eksklusif sebagai makanan utama bayi terutama pada usia 6 bulan pertama, dan tetap melanjutkan pemberian ASI kepada bayi sampai umur 2 tahun. Hal ini sesuai dengan pernyataan partisipan berikut ini:

"Dikasih ASI aja dia sampe sekarang, umurnya 6 bulan, dia kuat ASI"

(Partisipan 4)

Partisipan dalam penelitian ini juga mengatakan bahwa mereka memberikan susu formula khusus untuk memenuhi kebutuhan nutrisi bayi disamping memberikan ASI. Hal ini sesuai dengan pernyataan partisipan dibawah ini:

"Makan juga harus dijaga, minum susu dikasi sekali 2 jam kadang gak nyampe sejam udah nangis yah dikasi susu lagi makanya cepat naik berat badannya apalagi pas dikasi susu bebelac"

(Partisipan 6)

Partisipan mengatakan bahwa mereka memberikan makanan pendamping air susu ibu (PASI) setelah bayi berat lahir rendah berusia 6 bulan. Partisipan mengatakan bahwa mereka memberikan roti dan bubur. Hal ini sesuai dengan pernyataan partisipan sebagai berikut:

"Dibilang kuat ya biasalah, pagi nanti dikasih makan, kasih roti 1 biji, sore dikasih makan lagi terserah mau nasi ato bubur baru malam dikasih makan lagi, 4 kalilah satu hari dikasih makan, nanti dikasi satu sachet mp asi juga"

(Partisipan 8)

Salah satu partisipan mengatakan bahwa dalam merawat bayi berat lahir rendah harus hati-hati, teliti, dan mempertahankan kebersihan dari botol susu, pakaian dan air minum yang dikomsumsi oleh bayi. Hal itu dilakukan karena bayi berat lahir rendah masih sangat rentan terkena infeksi diakibatkan sistem imunitas yang belum matang. Hal ini sesuai dengan pernyataan dibawah ini:

"Ya pengalaman selama ini harus hati-hatilah harus bena-benar teliti, cara jagalah segalanya lah gimana minum susunya, botol susunya sebentar-sebentar harus direndam pake air panas dan air harus dimasak sendiri tidak boleh dari dispenser"

(Partisipan 6)

\subsection{Mengalami Keterbatasan dalam Kegiatan Sosialisasi}

Partisipan mengatakan bahwa mereka tidak bisa melakukan berbagai aktivitas saat bayi sakit, segala kegiatan terpaksa diabaikan dan ditunda terlebih dahulu. Partisipan mengatakan bahwa mereka tidak bisa pergi ke pesta, pengajian, belanja dan pekerjaan rumah terabaikan. Hal ini sesuai dengan pernyataan partisipan dibawah ini:

"Kesulitannya cuma pas mereka sakit aja, apalagi kalo ada keperluan mau pesta, disitu jugalah kendalanya, gak bisa pergilah kesana”

(Partisipan 10) 


\subsection{Menderita secara Fisik, Psikologis, dan Emosional}

Partisipan mengatakan bahwa mereka mengalami insomnia saat merawat bayi di rumah, hal ini disebabkan karena bayi sakit, tidak bisa melakukan sendawa setelah makan, dan bayi sering menangis. Hal ini sesuai dengan pernyataan partisipan dibawah ini:

"Dia dulu gak pande sendawa, udah ditepuk-tepuk juga gak akan keluar, jadi kakak tidurin di dada kakak, kakak tetap duduk sampe pagi, disuruh dokternya ditelungkupkan aja bayinya tapi kakak gak beranilah, kadang kan sampe kakak gak tidur pun, ya tapi gak susahnya cuma itu aja"

(Partisipan 1)

Partisipan lain juga mengatakan bahwa mereka merasa sedih karena bayi mereka kecil tidak seperti bayi-bayi normal pada umumnya. Hal ini sesuai dengan pernyataan partisipan dibawah ini:

"Hmm gimana ya, pasti sedihlah liat keadaan bayi saya yang kecil tapi karena dia utuh maksudnya gak kurang apapun ya agak tenanglah dikit"

(Partisipan 2)

Partisipan mengatakan bahwa saat merawat bayi berat lahir rendah mengalami baby blues dan merasa sensitif karena merasa diabaikan oleh keluarga. Hal ini sesuai dengan pernyataan partisipan di bawah ini:

"Habis melahirkan itu paling sensi ya melarlah perut jadi jeleklah inilah, udah itu sering gak tidur malam, merasa diabaikan abis lahir aja dulu aku dirame-ramekan pas dia lahir sunyi tinggal aku sendiri" (Partisipan 1)

\subsection{Mendapat Dukungan dari Pihak Keluarga dan Tenaga Kesehatan}

Partisipan yang menjadi objek penelitian, seluruhnya mendapatkan sumber dukungan dari keluarga. Terutama sumber perhatian dari orang-orang disekitarnya baik itu orang tua, suami, maupun keluarga lainnya. Hal ini sesuai dengan pernyataan partisipan dibawah ini:

"Mama kakak dia paling kalo namanya habis haid kan nyuciin baju anak saya sebelum tali pusarnya lepas yang mandiin bidan dekat rumah, trus mama juga ngerawat-ngerawat saya, buat jamu ntah apa gitu” (Partisipan 1)

Partisipan mengatakan bahwa mereka mendapat bantuan dari tenaga kesehatan dalam perawatan bayi berat lahir rendah di rumah. Hal ini sesuai dengan pernyataan partisipan dibawah ini:

"Kalo bidannya ya mandiin bayi saya terus diliatnya juga bayinya masih kuning ato gak. Sering diingrtin juga kalo pagi hari jangan lupa dijemur bayinya, pakein baju, seminggu sekali ditimbang sama dia biar liat perkembangan bayi saya" (Partisipan 3)

\section{Pembahasan}

Bagian ini akan diuraikan tentang pembahasan hasil penelitian dengan konsep atau teori yang ada, perbandingan dengan hasil penelitian yang pernah dilakukan sebelumnya berhubungan dengan pengalaman ibu usia remaja dalam merawat bayi berat lahir rendah di kota Medan. Partisipan lebih memilih membawa bayi yang sakit ke sarana pelayanan kesehatan, seperti dibawa berobat ke dokter dan bidan untuk mendapatkan pelayanan kesehatan. Hal ini sesuai dengan pernyataan Rasak [13] bahwa dalam proses penyembuhan biasanya ibu melakukan penyembuhan suatu penyakit dengan cara mengambil rujukan dari medis.

Partisipan yang menjadi objek penelitian mengatakan bahwa bayi pernah dibawa berobat kampung dan memberikan jamu kepada bayi berat lahir rendah. Hal ini sesuai dengan pernyataan Rasak [13] bahwa banyak orang tua, khususnya ibu mencari pengobatan di luar medis yang dipercaya mampu untuk menyembuhkan anggota keluarganya, dan hal ini juga dipengaruhi perasaan denial (penolakan) terhadap diagnosa medis terhadap kondisi anaknya. Hal ini juga sesuai dengan pernyataan Pramono [11] bahwa mengkomsumsi jamu memberikan efek positif 
terhadap kesehatan, tidak mengandung bahan kimia, tidak memiliki efek samping, dan diramu dari bahan-bahan yang disediakan dari alam, sehingga aman untuk dikomsumsi oleh bayi.

Partisipan mengatakan bahwa memberikan imunisasi kepada bayi berat lahir rendah merupakan suatu keharusan agar bayi tidak mudah terserang penyakit. Hal ini sesuai dengan teori yang dinyatakan oleh Atikah [1] bahwa imunisasi merupakan suatu upaya untuk menimbulkan atau meningkatkan kekebalan seseorang secara aktif terhadap suatu penyakit.

Partisipan mengatakan bahwa mereka tidak bisa melakukan berbagai aktivitas saat bayi sakit, segala kegiatan terpaksa diabaikan dan ditunda terlebih dahulu. Partisipan mengatakan bahwa mereka tidak bisa pergi ke pesta, pengajian, belanja dan pekerjaan rumah terabaikan. Hal ini sesuai dengan teori yang dinyatakan oleh Mansur [5] bahwa ibu yang memiliki bayi berat lahir rendah cenderung mengalami keterbatasan waktu bekerja karena harus mengurus anak, interaksi sosial juga berkurang karena banyak waktu yang dihabiskan untuk memberi perhatian kepada anaknya, mengalami keterbatasan gerak keluarga dalam bersosialisasi dan tidak bisa bebas bila ingin pergi kemanapun karena anak harus ikut.

Partisipan mengatakan bahwa mereka mengalami insomnia saat merawat bayi di rumah, hal ini disebabkan karena bayi sakit, tidak bisa melakukan sendawa setelah makan, dan bayi sering menangis. Hal ini sesuai dengan teori yang dinyatakan oleh Siswuharjo dan Chakhrawati [14] bahwa insomnia bisa timbul akibat dari kecemasan yang berlebihan akan kondisi bayinya yang dialami ibu pasca melahirkan.

Partisipan yang menjadi objek penelitian, seluruhnya mendapatkan sumber dukungan dari keluarga, terutama sumber perhatian dari orang-orang disekitarnya terutama orang rumah, baik itu orang tua, suami, maupun keluarga lainnya. Hal ini sesuai dengan teori yang dinyatakan oleh Perinasia [9] bahwa keluarga memegang peranan penting dalam asuhan bayi baru lahir, oleh sebab itu pelibatan keluarga harus menjadi bagian dari asuhan bayi baru lahir untuk memberikan rasa aman, meningkatkan kemampuan orang tua dalam merawat diri dan bayinya, dan mempromosikan kesejahteraan ibu dan bayi dengan memperhatikan keyakinan, nilai, tradisi, dan budaya yang dianut oleh keluarga. Hal ini juga sesuai dengan hasil penelitian Lee., Long, \& Boore [4] menunjukkan bahwa suami adalah pendukung utama dalam keluarga selanjutnya ibu kandung dan ibu mertua melengkapi dukungan.

Partisipan mengatakan bahwa mereka mendapat bantuan dari tenaga kesehatan dalam perawatan bayi berat lahir rendah di rumah. Hal ini sesuai dengan teori yang dinyatakan oleh Mok dan Leung [6] bahwa perawat dan bidan adalah tenaga kesehatan yang paling banyak berinteraksi dengan bayi dan keluarga harus memiliki pendekatan khusus dan memberikan asuhan kepada bayi baru lahir untuk membantu memenuhi kebutuhan fisik, sosial, psikologis, spiritual, ekonomis dari keluarga secara keseluruhan terhadap asuhan perawatan pada bayi.

\section{Kesimpulan}

Berdasarkan hasil wawancara mendalam yang dilakukan terhadap sepuluh partisipan, maka penelitian ini menemukan ada 5 tema terkait dengan pengalaman ibu usia remaja dalam merawat bayi berat lahir rendah di kota Medan, yaitu (1) mengupayakan pengobatan untuk BBLR; (2) memberikan perawatan khusus pada BBLR; (3) mengalami keterbatasan dalam kegiatan sosialisasi saat merawat BBLR; menderita secara fisik; (4) psikologis dan emosional saat merawat BBLR; dan (5) mendapat dukungan dari pihak keluarga dan tenaga kesehatan.

\section{Referensi}

[1] Atikah. (2010). Imunisasi dan Vaksinasi. Yogyakarta: Nuha Medika

[2] Ellya, E. (2010). Kesehatan Reproduksi Wanita. Jakarta: TIM

[3] Kusmiran, E. (2011). Kesehatan Reproduksi Remaja dan Wanita. Jakarta: Salemba Medika

[4] Lee., C. S., Long, A., \& Boore, J. (2009). Taiwanese Woman"s Experiences of Becoming A Mother to A Very-Low-Birth-Weight Preterm Infant: A Grounded Theory Study. Interrnational Journal of Nursing Studies, 46: 326-336

[5] Mansur, H. (2009). Psikologi Ibu dan Anak untuk Kebidanan. Jakarta: Gadjah Mada University Press

[6] Mok, E. \& Leung, S. F. (2006). Nurses as Providers of Support for Mothers of Premature Infants. Journal of Clinical Nursing. 15, 726-734

[7] Nabiwemba et al. (2014). Recognition and Home Care of Low Birth Weight Neonatus: a Qualitative Study of Knowledge, Beliefs, and Practices of Mothers in Iganga-Mayuge Health and Demographic Surveillance Site. Nurse Media Journal of Nursing. 1(2): 147-158

[8] Pantiawati, I. (2010). Bayi dengan BBLR (Berat Badan Lahir Rendah). Yogyakarta: Nuha Medika

[9] Perinasia (2010). Perawatan Bayi Berat Lahir Rendah (BBLR) dengan Metode Kanguru. Jakarta: Nuha Medika 
[10]Polit, D.F., \& Beck, C.T (2012). Nursing Research: Principles and Methods (7 th ed). Philadelphia: Lippincott

[11]Pramono, J. (2010). Jamu Ramuan Surga Plus Pijat Refleksi. Jakarta: TIM

[12] Proverawati, A. (2010). BBLR (Bayi Berat Lahir Rendah). Yogyakarta: Nuha Medika

[13]Rasak, M \& Natsir, S. (2013). Perilaku Pencarian Pengobatan di Kalangan Ibu Rumah Tangga dalam Menanggulangi Penyakit pada Balita di Binanga. Jurnal Fakultas Kesehatan Masyarakat UNHAS

[14] Siswuharjo, S \& Chakhrawati, F. (2002). Panduan Super Lengkap Hamil Sehat. Jakarta: Gramedia Pustaka Utama

[15] World Health Organization (WHO). (2014). Global Nutrition Targets 2025: Low Birth Weight Policy Brief . Geneva

[16] Kurnia, D. A. (2012) “Kolostomi, manajemen dan kualitas hidup untuk pasien”. 27 Juni 2013.

$\mathrm{http} / / /$ kesehatan.kompasiana.com/medis/2012/12/21/kolostomi-manajemen-dan-kualitas-hidupuntuk-pasien-512846.html 